\title{
The selecting of roofing material for pitched roofs by the analytic hierarchy process
}

\author{
Irina Romanova ${ }^{1, *}$, and Nataliya Skanavi ${ }^{1}$ \\ ${ }^{1}$ Moscow state university of civil engineering, Yaroslavskoye shosse, 26, Moscow, Russia, 129337
}

\begin{abstract}
Today's in the market of building materials there are a large number of roofing materials for pitched roofs. All of these materials have their advantages and disadvantages, so the task of choosing the optimal option is complex and requires special methods to eliminate the subjectivity of evaluation. The article describes the approach to selecting the best option of roofing material from the available options by the set of its quantitative and qualitative characteristics. It is proposed to carry out the evaluation of options and selection of the best option based on the analytic hierarchy process. The article presents the results of the selection of the most appropriate roofing material for pitched roofs using the specified method.
\end{abstract}

\section{Introduction}

The roof of the building is one of the most important structural elements that performs the protective and insulating functions (heat preservation and overheat protection, protection from external adverse factors - all types of precipitation, wind, melt water). There are two parts to a roof, its supporting structure and its outer skin, or uppermost weatherproof layer, which is directly exposed to atmospheric influences. This part of the roof shows great variation dependent upon availability of material [1].

The basic requirements to the roofing materials are [2-4]:

1. Weather resistance.

2. Watertightness- the ability of a material to pass water under a certain pressure for a certain time.

3. Water and frost resistance.

4. The strength of roofing material is the ability to carry dynamic (wind, atmospheric precipitation) and static (the weight of the snow masses, etc.) loads.

5. Biostability and corrosion resistance.

6. Good sound insulation properties - the ability to create reliable and highly efficient protection against external noise.

7. Durability.

8. Environmentally friendly.

9. Fire safety - an advantage have a non-combustible or slow-burning materials.

10. Efficiency.

"Correspondingauthor: nirs-isa@mail.ru 
11. Adaptability - it is possible to lower the complexity of works on roofing.

12. Aesthetic requirements - in the case of pitched roofs the roof is an important architectural element of the building.

In total, the concept of "aesthetic requirements" includes the so-called prestige of the material. Considered among the most prestigious materials such as ceramic tiles and natural slate. There are many materials that mimic ceramic tile, and even their name includes the word "tile": shingles, metal tile, cement-sand tile [5].

\section{Experimental section}

The materials for pitched roofs on the basis of its composition can be divided into mineral (cement concrete and clay roof tiles, asbestos cement sheets and tiles), metal (metal roof tile, profiled steel sheet, clicklock, composite roof shingles) and organic (asphalt shingle, onduline).

Clay roof tile is made of fired clay, it is durable (lifespan to 300 years), eco-friendly, non-combustible, has a high frost resistance and corrosion resistance. Because of their inherent thermal mass, clay roof tiles are able to absorb heat during the day and release it during the night, which makes them an energy efficient option in cooler climates. The disadvantages are the large weight cover $-50-65 \mathrm{~kg} / \mathrm{m}^{2}$, the brittleness, the complexity of installation and high cost [6]. Cement concrete tiles made of cement-sand mixture with the addition of mineral pigments by stamping or pressing. It is lighter than ceramic, but its lifespan is not so long (about 50 years). Slate (asbestos sheet) is obtained by molding mixture consisting of portland cement, asbestos fiber and water. It's cheap, durable, noncombustible, technological. The disadvantages are brittleness, high water absorption (material absorbs moisture, which leads bleaching and the growth of moss), the contents of asbestos. The latter is associated with unsatisfactory environmental friendliness of the material, although it is believed that the products asbestos is bound and not released into the environment [7].

Metal roofing materials consist of a galvanized steel sheet $(0.4 \mathrm{~mm}$ to $0.5 \mathrm{~mm}$ thick), coated on two sides by anti-corrosion (zinc, aluzinc or galfan) coating. Outer side is coated with a special polymer protective structure (metal roof tile) or colored granules of natural stone (composite roof shingles). The advantages of these materials are the low weight of the coating (4-5 $\mathrm{kg} / \mathrm{m}^{2}$ ), durability (lifespan is about 30-50 years), weather resistance, simplicity and speed of installation, aesthetics. The disadvantages of metal roofing materials (except composite tile) include poor sound insulation, high thermal conductivity, low stiffness of the coating, the possibility of corrosion damage of the protective coating, for example, during the installation and uneconomical - a large amount of waste (up to $40 \%$ ) when assembling a complex roof [8].

Asphalt shingles are made of a fiberglass mat coated with bitumen-polymer binder to both sides and on the front surface covered with colored mineral granules. Onduline is made of corrugated cardboard (or fiberglass), impregnated with bitumen-polymer binder and painted on the front side with weatherproof vinyl-acrylic paint. Advantages of organic roofing materials are low weight of the coating (less than $10-12 \mathrm{~kg} / \mathrm{m} 2$ ), simplicity and speed of installation, low cost, flexibility, good sound and thermal insulation. The disadvantages include combustibility (such materials are prohibited for use in most buildings of social importance (hospitals, schools, kindergartens, sports facilities)), low temperature brittleness, low stiffness of the coating, and for asphalt shingles, additionally, the need of continuous sheathing. A significant disadvantage of ondulin is bleaching in the sun [9-11].

Table 1 presents the most popular roofing materials for pitched roofs and their characteristics. The price includes the cost of the roofing material, the cost of installation 
(calculated for simple gable roof) and the cost of additional materials (truss, insulation, antiseptic, vapor barrier, consumables) $[12,13]$.

Table 1. Roofing materials for pitched roofs

\begin{tabular}{|c|c|c|c|c|c|c|c|}
\hline Roofing materials & 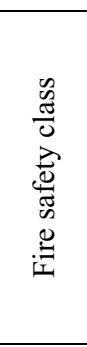 & 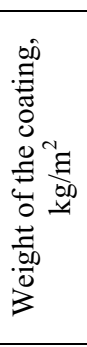 & 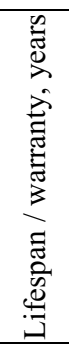 & 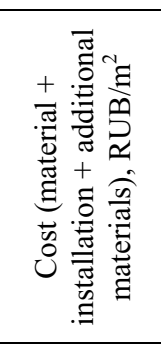 & 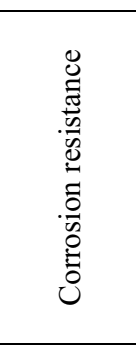 & 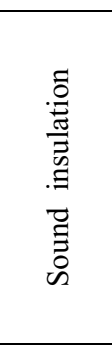 & 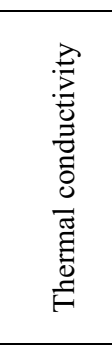 \\
\hline $\begin{array}{l}\text { Metal roof tile } \\
\text { Metal Profile } \\
\text { Monterrey } \\
\text { PURETAN }\end{array}$ & KM1 & 4.5 & $\begin{array}{l}50 / \\
20\end{array}$ & $\begin{array}{c}405+1200+ \\
1900= \\
3505\end{array}$ & good & low & high \\
\hline $\begin{array}{c}\text { ClickLock } \\
\text { Grand Line Satin }\end{array}$ & KM1 & 4.81 & $\begin{array}{c}20 / \\
10\end{array}$ & $\begin{array}{c}404+1150+ \\
1900= \\
3454\end{array}$ & $\begin{array}{l}\text { satisfacto } \\
\text { ry }\end{array}$ & low & high \\
\hline $\begin{array}{c}\text { Cement concrete } \\
\text { tiles Baltic tile Sea } \\
\text { Wave }\end{array}$ & KM0 & 43 & $\begin{array}{l}50 / \\
30\end{array}$ & $\begin{array}{c}356+1700+ \\
2200= \\
4256\end{array}$ & great & high & low \\
\hline $\begin{array}{l}\text { Clay roof tile Roben } \\
\text { FLANDERN }\end{array}$ & KM0 & 39 & $\begin{array}{c}100 / \\
30\end{array}$ & $\begin{array}{c}2185+1800 \\
+2300= \\
6285 \\
\end{array}$ & great & high & low \\
\hline $\begin{array}{l}\text { Asphalt shingles } \\
\text { Tegola Nordland, } \\
\text { Classic }\end{array}$ & KM5 & 9.5 & $\begin{array}{l}30 / \\
15\end{array}$ & $\begin{array}{c}240+1500+ \\
2200= \\
3940\end{array}$ & good & average & average \\
\hline $\begin{array}{c}\text { ONDULINE } \\
\text { roofing sheets } \\
\text { Onduline Tile }\end{array}$ & KM5 & 3.5 & $\begin{array}{c}25 / \\
15\end{array}$ & $\begin{array}{c}245+1200+ \\
2000= \\
3445\end{array}$ & good & average & average \\
\hline $\begin{array}{l}\text { Composite roof } \\
\text { shingles Decra } \\
\text { Decra classic }\end{array}$ & KM1 & 6.7 & $\begin{array}{l}50 / \\
30\end{array}$ & $\begin{array}{c}930+1700+ \\
2000= \\
4630\end{array}$ & great & high & average \\
\hline
\end{tabular}

All of these materials have their advantages and disadvantages, so the task of choosing the optimal option is complex and requires special methods to eliminate the subjectivity of evaluation. One of such methods is the analytic hierarchy process, which allows to solve the problem of choice on set of qualitative and quantitative characteristics [14-17]. The decision problem is decomposed into a hierarchy of more easily comprehended subproblems, each of which can be analyzed independently. The method is based on constructing a hierarchy starting from the top (goal), through intermediate levels (a group of factors or criteria that relate the alternatives to the goal) to the very bottom level (the list of alternatives for reaching the goal). Each element of the system, except for the top one, is subordinate to one or more other elements. The criteria can be further broken down into subcriteria, sub-subcriteria, and so on, in as many levels as the problem requires. Then the hierarchy is analyzed through a series of pairwise comparisons: the criteria are pairwise compared against the goal for importance, the alternatives are pairwise compared against each of the criteria for preference. The comparisons are processed mathematically: at each level the set of matrix of pairwise comparisons is built (table 2) [18].

Table 2. Matrix of pairwise comparisons

\begin{tabular}{|l|l|l|l|l|l|}
\hline & $A_{1}$ & $A_{2}$ & $A_{3}$ & $\ldots$ & $A_{n}$ \\
\hline
\end{tabular}




\begin{tabular}{|c|c|c|c|c|c|}
\hline$A_{1}$ & $w_{1} / w_{1}$ & $w_{1} / w_{2}$ & $w_{1} / w_{3}$ & $\ldots$ & $w_{1} / w_{n}$ \\
\hline$A_{2}$ & $w_{2} / w_{1}$ & $w_{2} / w_{2}$ & $w_{2} / w_{3}$ & $\ldots$ & $w_{2} / w_{n}$ \\
\hline$A_{3}$ & $w_{3} / w_{1}$ & $w_{3} / w_{2}$ & $w_{3} / w_{3}$ & $\ldots$ & $w_{3} / w_{n}$ \\
\hline$\ldots$ & $\ldots$ & $\ldots$ & $\ldots$ & $\ldots$ & $\ldots$ \\
\hline$A_{n}$ & $w_{n} / w_{1}$ & $w_{n} / w_{2}$ & $w_{n} / w_{3}$ & $\ldots$ & $w_{n} / w_{n}$ \\
\hline
\end{tabular}

$A_{1}, A_{2}, \ldots, A_{n}$ is the set of $\mathrm{n}$ elements and $w_{1}, w_{2}, \ldots, w_{n}$ respectively, their weight, or intensity. Weight, or intensity, of each element is compared with the weight or intensity of any other element of the set in relation to the common property or the goal (i.e. $w_{l} / w$ means comparison, not dividing the weights of these elements). The comparison of weights can be represented as follows: the elements of any level are compared with each other regarding their effects on guided element on 9-point scale (from 1 - equal importance to 9 - very strong superiority). If the element $A_{1}$ is dominant over the element $A_{2}$, the cell corresponding to the row $A_{1}$ and column $A_{2}$ is filled with an integer, and the cell corresponding to the row $A_{2}$ and column $A_{1}$ is filled with the integer reciprocal (fraction). Then at each level the synthesis of priorities is made, i.e. for each row the geometric mean is calculated. The vector of priorities is obtained by dividing each geometric mean by the sum of all geometric means (table 3) [19].

Table 3. Calculating of the vector of priorities

\begin{tabular}{|c|c|c|c|c|c|}
\hline & $A_{l}$ & $\ldots$ & $A_{n}$ & $\begin{array}{c}\text { The rating of the } \\
\text { eigenvector components } \\
\text { by row }\end{array}$ & $\begin{array}{c}\text { Vector of } \\
\text { priorities }\end{array}$ \\
\hline$A_{l}$ & $w_{l} / w_{1}$ & $\ldots$ & $w_{l} / w_{n}$ & $\sqrt[n]{\frac{w_{1}}{w_{1}} \times \ldots \times \frac{w_{1}}{w_{n}}}=a_{1}$ & $\frac{a_{1}}{\sum_{i=1}^{n} a_{i}}=x_{1}$ \\
\hline$\ldots$ & $\ldots$ & $\ldots$ & $\ldots$ & $\ldots$ & $\ldots$ \\
\hline$A_{n}$ & $w_{n} / w_{l}$ & $\ldots$ & $w_{n} / w_{n}$ & $\sqrt[n]{\frac{w_{n}}{w_{1}} \times \ldots \times \frac{w_{n}}{w_{n}}}=a_{n}$ & $\frac{a_{n}}{\sum_{i=1}^{n} a_{i}}=x_{n}$ \\
\hline
\end{tabular}

Multiplication of the matrix by the vector of priorities is as follows:

$$
\left(\begin{array}{cccc}
\frac{w_{1}}{w_{1}} & \frac{w_{1}}{w_{2}} & \ldots & \frac{w_{1}}{w_{n}} \\
\frac{w_{2}}{w_{1}} & \frac{w_{2}}{w_{2}} & \ldots & \frac{w_{2}}{w_{n}} \\
\cdots & \ldots & \ldots & \ldots \\
\frac{w_{n}}{w_{1}} & \frac{w_{n}}{w_{2}} & \ldots & \frac{w_{n}}{w_{n}}
\end{array}\right) *\left(\begin{array}{c}
x_{1} \\
x_{2} \\
\ldots \\
x_{n}
\end{array}\right)=\begin{gathered}
\frac{w_{1}}{w_{1}} x_{1}+\frac{w_{1}}{w_{2}} x_{2} \ldots+\frac{w_{1}}{w_{n}} x_{n}=Y_{1} \\
\frac{w_{2}}{w_{1}} x_{1}+\frac{w_{2}}{w_{2}} x_{2} \ldots+\frac{w_{2}}{w_{n}} x_{n}=Y_{2} \\
\ldots \\
\frac{w_{n}}{w_{1}} x_{1}+\frac{w_{n}}{w_{2}} x_{2}+\ldots+\frac{w_{n}}{w_{n}} x_{n}=Y_{n}
\end{gathered}
$$

It is important to note that in the matrix of pairwise comparisons there is no ratio $w_{i} / w_{j}$, there are only integers or integer reciprocals from a scale. This matrix in the general case is inconsistent. Algebraically the problem of consistency is the solution of the equation $A w=n w, A=\left(w_{i} / w_{j}\right)$, and the total task is the solution of the equation $A^{\prime} w^{\prime}=\lambda_{\max } \cdot w^{\prime}, A^{\prime}=\left(a_{i j}\right)$, where $\lambda_{\max }$ is the largest eigenvalue of the matrix of pairwise comparisons $A$. 
To check the consistency of each matrix the eigenvalues of the matrix are calculated (as the sum of the vector components obtained by multiplying the matrix of pairwise comparisons by the vector of priorities):

$$
\lambda_{\max }=\sum_{i=1}^{n} Y_{i}
$$

Next, the index of consistency (IC) and consistency ratio (CR) are calculated:

$$
\mathrm{IC}=\left(\lambda_{\max }-n\right) /(n-1),
$$

where $\lambda_{\max }$ - eigenvalue of the matrix, $\mathrm{n}$ - the number of compared elements.

where RI - random index.

$$
\mathrm{CR}=\mathrm{IC} / \mathrm{RI} \text {, }
$$

CR and IC should not exceed $10 \%$. Otherwise, the quality of the judgments should be improved, perhaps by revising the way in which questions are asked when conducting pairwise comparisons.

When conducting assessments it is important to keep in mind all compare items to comparison was relevant. To conduct a reasonable numerical comparisons should not compare more than $7 \pm 2$ elements.

Then hierarchical synthesis is conducted, i.e. the sum of all the weighted components of the corresponding eigenvectors of the hierarchy level lying before is calculated [20].

\section{Results section}

The described method was used for selecting the best option of roofing material for the device pitched roofs. The results are presented in table 4 .

Table 4. The results of the selecting the best option of roofing material

\begin{tabular}{|c|c|}
\hline Roofing materials & Global priorities \\
\hline $\begin{array}{c}\text { Metal roof tile } \\
\text { Metal Profile Monterrey PURETAN }\end{array}$ & 0,144 \\
\hline $\begin{array}{c}\text { ClickLock } \\
\text { Grand Line Satin }\end{array}$ & 0,116 \\
\hline Cement concrete tiles Baltic tile Sea Wave & 0,149 \\
\hline Clay roof tile Roben FLANDERN & 0,236 \\
\hline Asphalt shingles Tegola Nordland, Classic & 0,071 \\
\hline $\begin{array}{c}\text { ONDULINE roofing sheets } \\
\text { Onduline Tile }\end{array}$ & 0,144 \\
\hline Composite roof shingles Decra Decra classic & 0,142 \\
\hline
\end{tabular}

\section{Discussion section}

Thus, the best option by the set of its characteristics is clay roof tiles Roben FLANDERN, its disadvantages are high cost and a large mass of $1 \mathrm{~m}^{2}$, however, durability, fire safety, environmental friendliness, corrosion resistance, sound insulation and thermal conductivity are significantly ahead of other options of roofing materials. Metal roof tile Metal Profile PURETAN Monterrey, ONDULINE roofing sheets Ondulin Tile, Cement concrete tiles Baltic Sea Wave tile and composite roof shingles Dekra Dekra classic have approximately equal values of global priorities. The least successful of the above options can be considered the Asphalt shingles Tegola Nordland, Classic - its disadvantages are high cost with a relatively small lifespan and high combustibility. 


\section{Conclusions}

The proposed technique can be applied for selection of the most appropriate building material or technological equipment from the available options based on its qualitative and quantitative characteristics.

\section{References}

1. J. Testa, M. Krarti, Sust. Cities and Soc., 31, $62-73$ (2017)

2. J. Y. Lee, G. Bak, M. Han, Envir. Poll., 162, 422-429 (2012)

3. B. Vale, Ecol.and Sust. Built Environ., 2, 67-112 (2017)

4. P. Berdahl, H. Akbari, R. Levinson, W. A. Miller, Constr. and Build. Mater., 22(4), 423-433 (2008)

5. S. Pișkin, A. K. Figen, E. özkan, ü. Özçay, IFAC Proc. Vol., 46(16), 484-487 (2013)

6. V. Ducman, A. S. Škapin, M. Radeka, J. Ranogajec, Ceram. Int., 37(1), 85-91 (2011)

7. S. Emmitt, C. A. Gorse, Barry's Intr. to Constr. of Build, 1, 208 (2013)

8. M.I. Sánchez de Rojas, F.P. Marín, M. Frías, E. Valenzuela, O. Rodríguez, Constr. and Buildi. Mater., 25(6), 2888-2897 (2011)

9. A. Arnold, Proc. Eng., 145, 760-765 (2016)

10. C.R. Dixon, F.J. Masters, D.O. Prevatt, K.R. Gurley, T.M. Brown, J.A. Peterka, M.E. Kubena, J.of Wind Eng. and Industrial Aerodyn., 130, 30-40 (2014)

11. B. Nam, H. Maherinia, A. H. Behzadan, Constr. and Buildi. Mater., 50, 308-316 (2014)

12. Available at: http://krovlja.ru/

13. Available at: http://smol-krovlya.ru/

14. S. Rahman, H. Odeyinka, S. Perera, Y. Bi, Exp.Syst.with Appli., 39(8), 6857-6871 (2012)

15. I. Kafiev, P. Romanov, Bull. Bashkir Univ., 2(26), 83-86 (2013)

16. I. Kafiev, P. Romanov, I. Romanova, Bull. Bashkir Univ., 3(35), 48-52 (2015)

17. I. Kafiev, P. Romanov, I. Romanova, Bull. Bashkir Univ., 1(33), 82-90 (2015)

18. T. L. Saaty, RACSAM, Series A: Mathematics, 102(2), 251-318 (2008)

19. B.O. Saracoglu, Eur. J. of Ind. Eng. Ind. Enter., 7(4), 416-441 (2013)

20. Z. Q. Geng, S. S. Zhao, G. C. Tao, Y. M. Han, Appl. to food safety, 78, 33-42 (2017) 